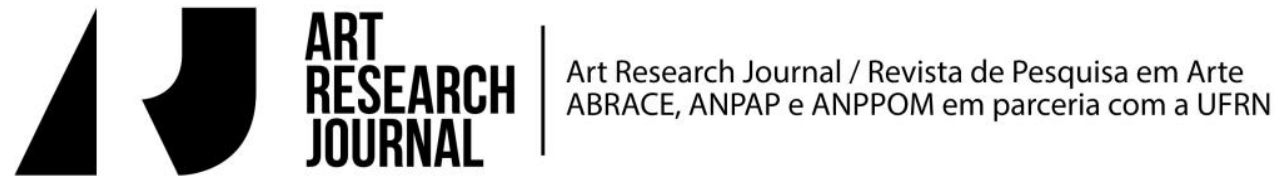

\section{Pesquisa Somático-Performativa: \\ Sintonia, Sensibilidade, Integração}

Ciane Fernandes

PPGAC-UFBA/CNPq

A Pesquisa Somático-Performativa busca consolidar as artes cênicas não apenas como campo de produção de conhecimento científico, mas, antes, como campo de criação de Sabedoria Somática (Nagatomo, 1992), coerente com a natureza das artes, que a tudo permeia, e com aplicações irrestritas. Com frequência, usamos autores de várias áreas do conhecimento para legitimar nossas pesquisas. Porém, a maioria desses autores não é artista - pelo menos não como opção primeira e fundante -, e utiliza a arte como objeto de ilustração ou mesmo se apropria de termos artísticos para compor teorias de outros campos. Esta configuração é politicamente incorreta e perpetua modos limitantes de ver e viver. Ela subtende o campo das artes como puramente prático, a ser analisado e citado pelos "pensadores", ou exaltado como objeto do desejo, confirmando sua marginalização, além de reforçar a dicotomia entre fazer e pensar, corpo e mente, Real e Simbólico.

Nossa justificativa para aquela fundamentação teórica extra-artes é, em geral, o argumento de que somos um campo recente de pesquisa e, portanto, não temos um arcabouço próprio e precisamos nos basear em áreas mais consolidadas para legitimar nossas pesquisas. Isso é ainda mais grave quando se trata de uma metodologia emprestada de outras áreas. Isto porque a metodologia norteia e organiza (nesse caso, manipula e distorce) todo o material artístico sob perspectivas históricas, filosóficas e políticas não apenas diversas do tema artístico, mas cuidadosamente dominador e doutrinário deste. Para completar o 
processo traumático, esse empréstimo é acrescido do discurso enganoso de emancipação da arte através da pesquisa científica.

A crença de que as artes - mais especificamente as cênicas - não tem um arcabouço próprio, baseia-se nos primórdios das artes cênicas na pós-graduação brasileira, quando poucos tinham acesso a uma pós-graduação específica na área, nossa produção era ínfima, e mesmo a formação na graduação era limitada, com a maioria de nós tendo graduação em áreas afins e apenas formação técnica em artes, além do fato de que a graduação em artes cênicas em geral não tinha disciplinas voltadas para a pesquisa. Mas este quadro vem mudando rápida e radicalmente nas últimas décadas, e precisamos derrubar esse preconceito e atualizar nossa auto-imagem com urgência. Além disso, precisamos perceber como essa negação da história da pesquisa em artes cênicas - que já vem se desenvolvendo a mais de dois milênios ${ }^{1}$ - é uma atitude de auto-invalidação e auto-rejeição, que precisa ser radicalmente transformada.

Enquanto continuarmos a usar outros campos como fundamentos para nossa pesquisa, continuaremos a legitimar nossa auto-marginalização e a dicotomia entre fazer e pensar, serviço braçal e atividade intelectual, com desvalorização da primeira e hegemonia da segunda. O artista-pesquisador tem uma habilidade única: transformar dicotomias seculares em modos somáticos e ecológicos de vida contemporânea. O termo somático não exclui desenvolvimentos cada vez mais recentes, como os da tecnologia e da era digital. Pelo contrário, somático (do termo soma ou corpo vivido) implica numa adaptação constante a mudanças, num estado de integração dinâmica entre ser e meio - ambos categorias vivas: "Organismos vivos ... têm uma ordem movente e uma lei deles mesmos ... eles são um processo integral e ordenado de elementos incorporados que não podem ser separados quer seja do passado evolutivo ou do futuro adaptativo." (Hanna, 1976, p. 31).

Associada ao soma, a performance não apenas constitui-se como ato ou evento que desconstrói o simulacro e atravessa o Simbólico em todas as suas instâncias, mas contribui de forma politicamente efetiva para a contemporaneidade, inovando modos de operar questões eminentes e insistentemente

\footnotetext{
1 Referimo-nos aqui ao quinto Veda ("eu vi"), o Nātya Śāstra (Teoria da Dramaticidade, de Bharata Muni), o mais antigo e completo tratado sobre as artes cênicas, com 5.800 versos, datado de 200 anos antes de Cristo, durante a civilização védica.
} 
negligenciadas, como a sustentabilidade, a inclusão, a disritmia e insatisfação generalizadas, entre outras.

As artes hoje têm meios de estabelecer seus próprios métodos e abordagens, atualizando contextos e desmontando preconceitos ultrapassados de pesquisa que nos usam como objeto para discutir mudanças dentro de formatos engessados, portanto sem condições efetivas para realizá-las. Assumindo nossos próprios métodos, nos tornamos sujeitos de nossa própria história, e podemos inverter essa lógica colonizadora e hegemônica e passar a influenciar os demais campos em meios e modos bem mais flexíveis e coerentes com uma (nova) realidade contemporânea.

Se arte é mediação, é justamente a arte contemporânea que nos reconecta com o real - não apenas numa estética do choque (Féral, 2012) que reconstrói a violência cotidiana, mas precisamente como uma transgressão a ela, re-criando novas possibilidades de realidades sensíveis. Se o mundo contemporâneo tornou-se um império do simulacro, do aumento crescente, descontrolado e avassalador de informações em velocidade atordoante em meios múltiplos e diversificados (Santaella, 2012), é justamente a arte enquanto pesquisa que instaura um campo sensorial de experiência e liberdade identitária num Retorno ao Real (Foster, 1996) imprevisível e fundamental.

Para ser cientista e/ou fazer pesquisa, um artista não precisa - apesar de poder - usar o que comumente denomina-se de "ciência" - que equivocadamdente é associada apenas às ciências duras - que, aliás, vêm apresentando "ondas" e "incertezas" cada vez mais flexíveis e desestruturantes (Kako, 1995; Prigogine, 1996). A arte conceitual - bem como suas origens na performance e nos manifestos, e em toda a história da abstração na arte - desassociou o objeto e/ou ação estética de sua aparência, ao invés disso usando-a em forma de autoquestionamento e constante re-indefinição. Transfere-se, assim, o foco da arte como objeto e/ou ação para fruição, para a arte como articuladora de princípios e questões do fazer e do viver, integradora e transgressora - e isto inclui as mais variadas tradições culturais que, no contexto contemporâneo, são altamente inspiradoras. A postura ético-estética contemporânea confirma a "atividade humana, criativa e inovadora ... como uma amplificação de uma intensificação de traços já presentes no mundo físico." (Prigogine, 1996, p. 74). 
Venho denominando essa intensificação - característica da cena e da performance - de "pulsões espaciais" (Fernandes, 2014), baseada nas duas principais categorias criadas por Rudolf Laban - a "Eukinética" (expressividade ou dinâmica) e a "Corêutica" (formas visuais criadas pelo movimento no/com o espaço) -, que associadas (re)criam um espaço dinâmico ("Dinamosfera"). Mesmo "parados", estamos em constante adaptação de forças espaciais dinâmicas multidirecionais e integradas. Porém, precisamos expandir nossa possibilidade de pulsão espacial para pontos e percursos pouco usados nos movimentos repetitivos e limitantes do dia-a-dia, estimulando o crescimento através da relação entre estrutura e criatividade, forma e dinâmica, matéria e energia.

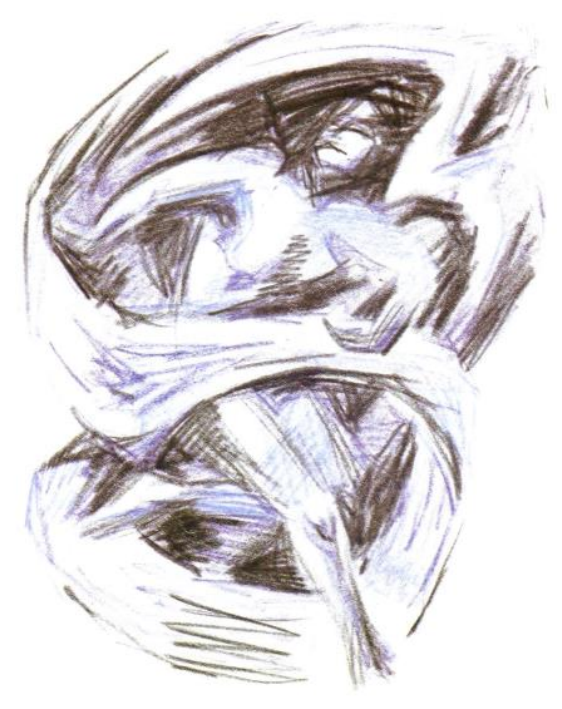

Figura 01. Espaço Dinâmico (Laban, 1984, capa).

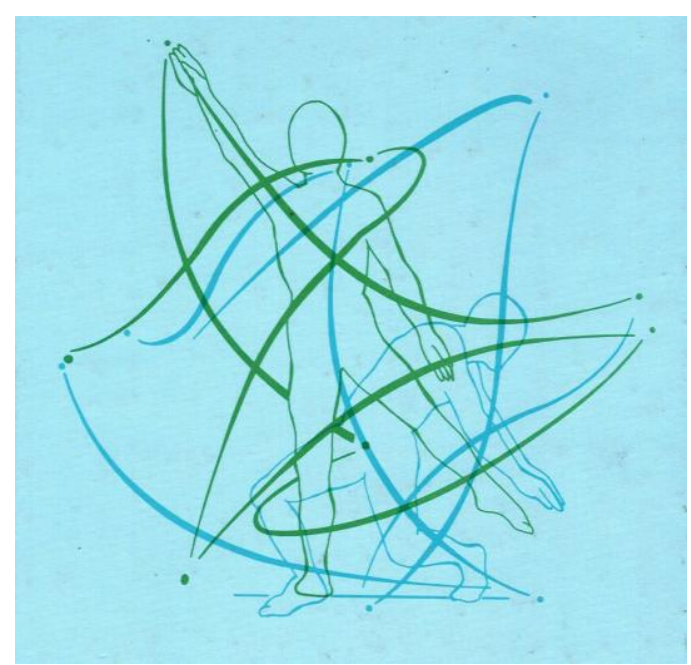

Figura 02. Uma das escalas espaciais do Icosaedro (Bartenieff e Lewis, 1980, capa). 
Em pulsões espaciais, experiência e sentido (Bondía, 2002) atravessam e conectam mineral, vegetal, celular, cósmico, digital, sintético, escrito, técnico, processual, midiático, cena, público etc. Mais importante do que a presença (do performer e/ou do público) ou mesmo a efemeridade (dos eventos e/ou da observação da obra), é como se processam determinados estados intensos (mesmo que em uma sutileza, suavidade ou vagarosidade agudas) - na arte e na vida (e na pesquisa que atravessa e conecta a ambas), mesmo que - e justamente - na ausência do performer (como numa "perforgrafia"2), na pausa do dançarino, no silêncio do ator, na dança de um texto, na cena ao ar livre, ou numa obra de arte que não é mais vítima do tempo. Hoje, pelo contrário, a arte evolui quase que mais rápido que o tempo, reinventando-o.

O contraste inerente à arte a define não apenas como ação em suas diversas esferas, mas como pulsão - entre pausa e ação, em ondas de expansão e contração, como universos em crescimento. Em Padrões de Mudança ou Crescimento - que venho denominando de "Padrões Cristal" (Fernandes, 2012a), baseada nas formas cristalinas da Corêutica -, a vida se transforma ao se repetir (ou melhor, reconstruir), paradoxalmente definindo seu próprio modus operandi ao se multiplicar no diferente.

A arte concretiza esse paradoxo da existência mesmo na pintura mais linear, enquanto conceito inerente. Sua negação de função, sua irreverência separatista e radicalmente invasora, sua constituição organicamente única e identificada com tudo e todos, particular e universal, a torna matriz-motriz da vida.

Este estado pulsante ou processo vital de pesquisa caracteriza tanto a arte de ênfase somática, quanto a arte transcultural, ou a arte de enfoque tecnológico ou digital, ou ambiental, terapêutica, entre outras tantas tendências, ou a associação de diferentes ênfases em diferentes graus. Nenhuma delas tem primazia sobre a outra no que diz respeito a ser mais ou menos eficiente, coerente, relevante, ou mesmo contemporânea. Todas essas tendências são contemporâneas, não apenas porque acontecem hoje, mas porque são efetivamente outras com relação a suas versões anteriores, e são necessariamente permeáveis à mudança e abertas à inevitável

\footnotetext{
2 Neologismo usado para denominar uma fotografia que perpetua o modus operandi dinâmico da performance. (Fernandes, 2014).
} 
contaminação pela diferença. Seria uma ilusão - e aí sim, uma atitude não contemporânea - insistir na dicotomia entre tradição e contemporaneidade, bem como num tempo linear que nos impele a inovar como rejeição da história (do corpo, da cena, da pesquisa, enfim). É justamente esse tempo produtivo e nossa subserviência a ele que deve ser mudada, para que estejamos de fato livres - como artistas devem ser - da produção quantitativa, compulsiva e compulsória, repetitiva e irrelevante, que tem se disseminado diante das pressões - estas sim - tradicionalistas.

Mais importante do que categorias - como dança, teatro, performance etc. -, ou enfoques - como somático, cultural, tecnológico, terapêutico, ambiental, histórico etc. - é a ênfase na arte como pesquisa, ou seja, como estados dinâmicos, imprevisíveis e auto-organizantes de criatividade, atualização e compartilhamento, em qualquer que seja a mídia ou abordagem. Essa inovação através da pesquisa não é uma nostalgia futura (Schechner, 2010), como um desejo sempre projetado e um Real escapante. No "espaçotempo" quântico, atualização é memória em constante e simultânea realização, desaparecimento e auto-poiesis relacional, num encontro dinâmico imprevisível com o Real.

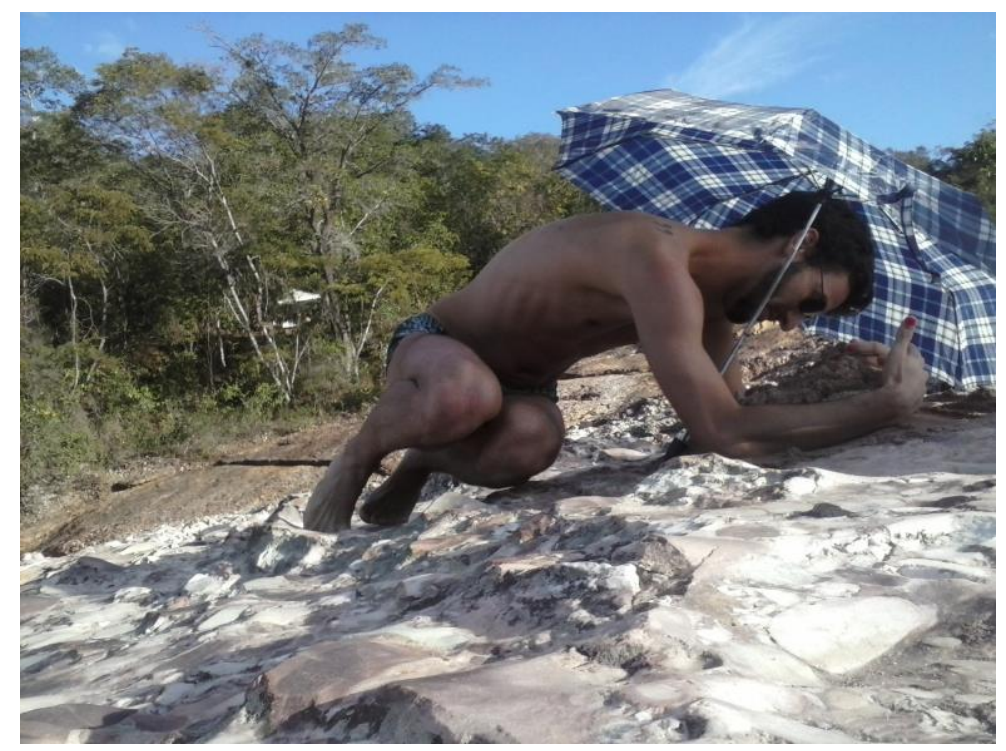

Figura 03. Leonardo Paulino desenvolvendo sua pesquisa de gênero no Laboratório de Performance do PPGAC/UFBA em Lençóis BA, julho de 2013. Foto da autora.

Assim, a "pesquisa-arte" (mais do que "artística" ou "em artes") é uma "pesquisa em movimento": ${ }^{3}$ seu tema é seu método, seu objeto é seu sujeito. Por isso, a

3 "Movimento" no contexto somático é compreendido como a dinâmica entre ebulição e pausa, mobilidade e estabilidade. 
arte deve ser o fundamento de sua pesquisa, agregando e dialogando com todo e qualquer campo a partir desse elemento-eixo constitutivo, que se (des)(re)organiza. A liberdade irrestrita da arte é única dentre todos os campos, mesmo que - e justamente porque - suas origens tenham sido divinas, funcionais e sociais. Daí a pertinência do termo somático-performativo, enquanto pulsão espacial e integração, e sua aplicação irrestrita.

Saliento que o uso desse novo termo híbrido - "somático-performativo" - não decorre da busca por inventar um novo paradigma ou modelo a ser seguido. Muito pelo contrário, surge de uma necessidade real de diluir fronteiras entre campos artificialmente separados que atrapalham o fluxo da vida, da arte e da pesquisa. Assim, essa terminologia busca legitimar uma abordagem aberta, inclusiva e em constante transformação. Apesar de trazer o conforto da aceitação, essa abordagem propõe o desafio como estímulo ao crescimento ou mudança, tanto quanto o fazem a educação somática, a dança-teatro e a performance.

A Pesquisa Somático-Performativa fundamenta-se na educação somática e na performance para criar um arcabouço das artes cênicas para as artes cênicas, em diálogo ilimitado com outras áreas do conhecimento. A Pesquisa SomáticoPerformativa insere-se no contexto da Prática como Pesquisa (PaR; Barrett e Bolt, 2007), e relaciona-se diretamente com a Pesquisa Performativa e a Pesquisa Somática e, em menor grau, com a Somaestética.

Enquanto a Somaestética se divide nos eixos analítico, pragmático e prático (Schusterman, 2008), a Pesquisa Performativa é um "multi-método guiado pela prática" (Haseman, 2006), onde esta não é um adicional extra no qual se aplica e testa determinados princípios ou conceitos como nas pesquisas qualitativa e quantitativa. A Pesquisa Somático-Performativa, por sua vez, é guiada pela prática somática, com total sobreposição das três instâncias divididas na Somaestética.

O termo Somática (Somatics) inspira-se na palavra grega para "corpo vivido" ("Somatikos"), que por sua vez inspira-se na bebida sagrada relatada nos Vedas (soma), e reinterpretado como o corpo experienciado internamente. O termo foi usado pela primeira vez por Thomas Hanna em 1976, para descrever abordagens de integração corpo-mente que ele e outros terapeutas e educadores estavam desenvolvendo. São algumas das premissas da Somática:

Todos os somas são processos holísticos de estrutura e função, em constante troca entre matéria e energia; somas tendem 
simultaneamente a homeostase e equilíbrio enquanto tendem à mudança e desequilíbrio, num paradoxo que caracteriza e produz a vida; todo processo somático acontece em padrões rítmicos cíclicos de movimento interno alternante (por exemplo, sístole/diástole, expansão/contração, parasimpático/simpático, sono/vigília); na ecologia somática, o soma tende à autonomia e independência de seu ambiente enquanto tende a desejar e depender dele - tanto social quanto fisicamente; todos os somas crescem numa alternância entre funções adaptativas analíticas e sintéticas rumo à diferenciação; somas coordenam suas partes holisticamente, intencionando seu crescimento, diferenciação e integração. (Hanna, 1976, p. 32).

Integração é um fundamento de várias técnicas somáticas. A partir da obra pioneira de Irmgard Bartenieff - discípula de Rudolf Laban (Bartenieff e Lewis, 1980) -, Peggy Hackney (1998) diferenciou a "abordagem integral" de outras três abordagens - unidade, muitas partes articuladas, complexidade estratificada. Na "integração", os diversos elementos criam um sentido a partir da inter-relação de suas integridades cooperativas, respeitando as inteligências múltiplas em suas diferenças num todo dinâmico. Além disso, é interessante perceber como todos os termos usados no Sistema Laban/Bartenieff surgiram (e continuam surgindo) de exercícios exploratórios realizados e posteriormente sistematizados em um arcabouço somático de aplicação na pesquisa, notação e escrita.

A Somática advém do Movimento Corporalista, no início do século XX, com pioneiros como Laban, Alexander e Feldenkrais. A partir desse Movimento, a ênfase deixou de ser tanto em um gênero ou estilo de arte, mas no ser humano compreendido em sua totalidade da experiência, em inte(g)ração com o ambiente. Cada vez mais plurais em suas potências, as artes minaram todos os limites preconcebidos do que cabe à arte ser ou não ser (Santaella, 2012, p. 63), em prol de uma estética de sensibilização pessoal e consciência planetária: "Ética é a estética do futuro." (Anderson, 1993).

Pesquisa Somática seria a pesquisa realizada pelos profissionais que atuam no âmbito da educação somática, que vem se consolidando como um campo autônomo e científico nas últimas décadas. A Pesquisa Somática é implicitamente especificada pelos princípios da educação somática, porém seu método de investigação per se coleta, análise e discussão de dados - confunde-se com procedimentos educacionais e terapêuticos, continua nebuloso e muitas vezes usando modos já consagrados (e ultrapassados) de pesquisa. Mesmo assim, reside na porosidade somática alguns dos fundamentos de uma revolução na academia. 
Cabe ao artista-pesquisador contemporâneo valorizar o "discurso alternativo", pessoal e experiencial (Fortin, 2012, p. 134), integrando-o no contexto acadêmico. Isto não significa criar mais um discurso hegemônico, mas sim em fomentar um fluxo relacional conectivo entre experiência, discurso e contexto que atravessa vida, arte e pesquisa. Inclusive porque o fator fluxo ou fluência (Laban, 1971) é subliminar aos demais fatores expressivos (peso, tempo, foco) e suas combinações, constituindo e conectando matéria e energia (soma).

Inspirada na fenomenologia e na Somática, a "escrita incorporada" (Anderson, 2002) baseia-se na experiência transpessoal, intuitiva e sensorial (incluindo propriocepção ou felt sense e cinestesia), contra modos desincorporados de escrever que reafirmam o dualismo entre sujeito e objeto, ser e mundo. A proposta somática de Anderson alinha-se com a psicologia humanística, transpessoal e positiva, e pode ser aplicada a pesquisas qualitativas transdisciplinares nas artes, com resultados inovadores (Anderson, 2002-2003).

Apesar de lançar bases para uma transformação efetiva na pesquisa e na academia, a Pesquisa Somática não emerge da arte, não a inclui como método constitutivo, e não objetiva a criação ou inovação artística. No entanto, suas bases confundem-se com as das artes em sua ênfase na experiência, na intuição, na integração ser-meio, no aspecto transpessoal e na criatividade. Assim, podemos usar sua audácia sutil para questionar meios cartesianos de se fazer pesquisa (como, por exemplo, questionar o ato de escrever como prioritariamente cognitivo); mas é preciso buscar meios criativos autônomos, baseados na questão estética e desvinculados de uma função analítica a priori.

Já a Somaestética (Shusterman, 2008) vem preencher uma lacuna no pensamento filosófico ocidental, atualizando-o em consonância com o campo pioneiro e integrador da educação somática. Apesar de apresentar conceitos pertinentes à pesquisa em artes cênicas, a Somaestética não parte da prática artística - que continua a ser objeto de análise ou um "adicional extra", ao invés de sujeito organizador do processo (de pesquisa, de estudo etc.) e objetivo.

Este é o diferencial entre Laban e maioria das práticas somáticas: Laban era um artista da cena que fundou as bases de uma Arte do Movimento, inclusive o título original de seu livro era O Domínio do Movimento no Palco (The Mastery of Movement on the Stage, 1950). Já a maioria das técnicas de educação somática são conhecidas como sendo de cura, mesmo que podendo ser aplicadas no 
treinamento do artista cênico, ou tendo alguma relação com as artes em seu histórico. No entanto, este quadro vem mudando e, cada vez mais, abordagens somáticas vêm sendo associadas a práticas estéticas. Daí a pertinência histórica da associação entre somática e performance: a obra de Laban fez parte dos primórdios de ambas (Prevots, 1985), e seus aprimoramentos irrestritos continuam dialogando com os dois campos, que podem e precisam ser integrados na contemporaneidade.

A Pesquisa Somático-Performativa é fundada nas artes cênicas, numa abordagem MIT-disciplinar ${ }^{4}$ a partir da Análise Laban/Bartenieff em Movimento (Laban/Bartenieff Movement Analysis - LMA). A partir do aspecto dinâmico da arte, venho traduzindo movement analysis para análise em movimento (ao invés de análise de ou do movimento), e usado Movement Studies como Moving Studies, o que implica numa "co-moção", e sua tradução para Estudos em Movimento ou Co-Moventes. Esta mudança terminológica sutil implica numa transformação epistemológica radical, pois o objeto de análise passa a ser o modus operandi de todo o processo, ou seja, torna-se sujeito ativo de sua própria história, desconstruindo maneiras de dominação sobre ele (no caso, nós, seres vivos, constituídos de pulsação) em um processo dinâmico de pesquisa.

Isto é fundamental se lembrarmos que, como nos alertou Bartenieff, todo aprendizado é realizado através do movimento, em movimento: "Movimento, não mais ponderação, é o que traz novo conhecimento" (Irmgard Bartenieff in Hackney 1998, p. 3). Então estamos (des)(re)organizando nossos modos de ser e viver no mundo. A este processo, Bartenieff chamou de "repadronização" (repatterning), pois ocorre a partir da re-experiência de Padrões de Crescimento ou Padrões Neurológicos Básicos (da célula até a bipedia), revivendo a história da evolução das espécies durante nossa gestação e primeiro ano de vida, no caso, em aulas de educação somática.

A repadronização ou revivência desses Padrões de Crescimento ou Mudança revigora um princípio fundamental do desenvolvimento neuro-cinesiológico: o movimento corporal é a matriz do desenvolvimento cognitivo, a maneira através do qual este último se efetiva e se integra no soma. Enquanto Descartes postulou que "penso, logo existo", e Lacan sugeriu que "penso, logo desconecto-me do Real", na educação somática inferimos que "movo-me, logo aprendo com/no meio".

4 Conjunto de abordagens (Multi-Inter-Trans ou MIT) conferindo um novo olhar sobre as disciplinas. (FARIAS, 2012). 


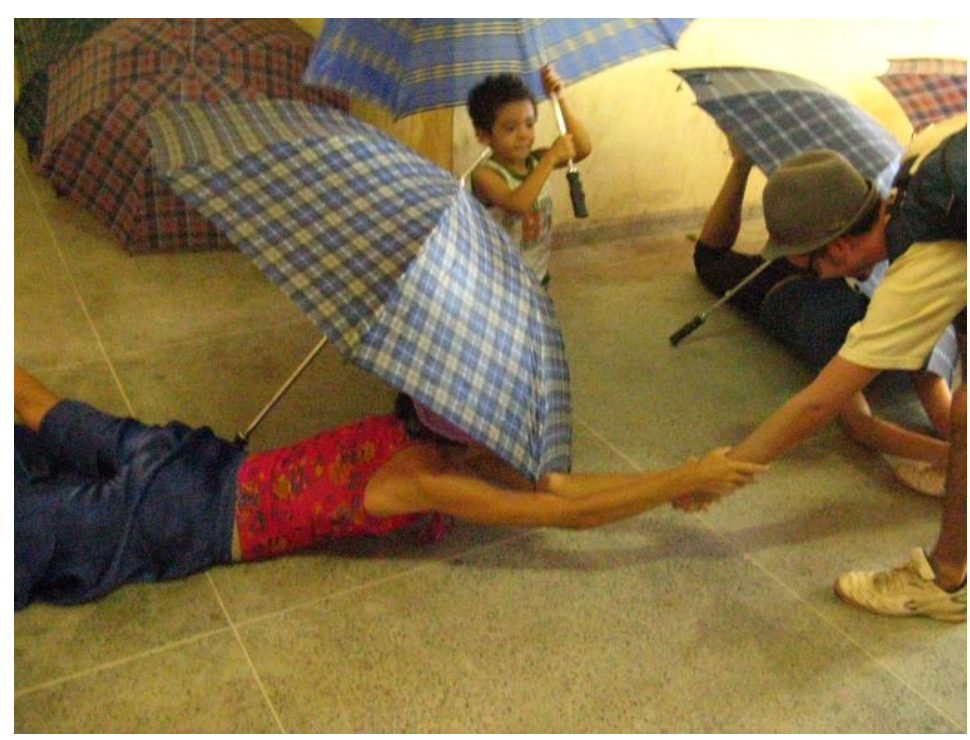

Figura 04. Ciane Fernandes e Lenine Guevara em atividade do Laboratório de Performance na feira de Lençóis BA, abril de 2011. Foto de Carolina Érica Santos.

Além disso, essa terminologia "em movimento" subtende duas premissas tão importantes quanto a associação delas em todos os nossos níveis constitutivos: 1) movimento como dinâmica entre "Ebulição e Pausa" (poema de Laban de 1939, publicado em 1984, p. 68), em nuances de Ritmo, 2) em consonância com a criação de laços afetivos. Como nos esclareceu Laban, já em 1921:

Ritmo é a lei do gesto, de acordo com o qual ele se procede uma vez de maneira mais fluentemente e outra vez menos fluentemente, em sua sequência no espaço dentro de uma sequência de tempo (duração). Como um resultado, tensionar e destensionar (relaxar) originado dentro do todo do corpo são nuances de força. (Laban, 1921, p. 55).

Dra. Judith Kestenberg (1965; 1977), aluna de Laban, desenvolveu essa noção de Ritmo em uma complexa teoria baseada no desenvolvimento das diferentes funções orgânicas desde a vida intrauterina até a fase adulta, integrando função e expressão, os diferentes sistemas do corpo e o movimento visível (mesmo que - e principalmente - em pequenas modulações e nuances mínimas). A partir de variações expressivas entre tendência condensada (menos "fluentemente" ou com fluxo contido subliminar: forte, direto, acelerado) e entregue ou indulgente (mais "fluentemente" ou com fluxo livre subliminar: leve, indireto/flexível, desacelerado), presentes na Eukinética de Laban (Laban e Lawrence, 1974), Dra. Kestenberg expandiu e reorganizou as fases identificadas por Sigmund Freud (oral, anal, fálico-edipiana, latência, genital), apontando dois padrões rítmicos em cada uma delas (Kestenberg, 1975). 
Além dos dez ritmos básicos, cuja notação varia como em um eletrocardiograma, existe uma infinidade de outras possibilidades, caracterizando o fluxo de nossas pulsões em relações afetivas com o meio, como, por exemplo, os Ritmos de Gratificação (Kestenberg, 1977), que se desenvolvem como ondas imprevisíveis de prazer.

Enquanto pulsão espacial, arte e pesquisa dividem a mesma força matriz-motriz da vida. Sim, estamos falando de sexualidade(s) - aquela(s) cuja história de manipulação tem (de)formado em corpos dóceis (Foucault, 1990). Precisamos transferir a ênfase cognitiva e dualista do sistema educacional (da pré-escola à pós-graduação) para forças sensíveis integradoras, em sintonia com nossos ritmos internos, em conexão com pulsações ambientais orgânicas e inorgânicas, micro e macrocósmicas, para que possamos mudar a história de dominação do corpo e nos transformarmos em somas, aliás, somático-performativos. A pesquisa-arte tem todas as condições para realizar essa mudança rumo a uma "ecologia somática" (Hanna, 1976) ou, ainda, uma "ecologia profunda" (Antolick, 2003). A busca por desenvolvimentos pós-humanos deve ser resultado de uma necessidade criativa, não da extinção de vida no planeta decorrente da devastação da natureza e de catástrofes ambientais.

Segundo Hackney, Bartenieff andava com um broche com a afirmação: "A mudança está aqui para ficar" (Hackney 1998, p. 16). A partir desse estado de mobilidade estável ou estabilidade móvel, Hackney nos instiga a elaborar modos de viver num mundo em "constante mudança". Pesquisar hoje é aprender a lidar com esse estado paradoxal de encontrar estabilidade na mobilidade e vice-versa. Como nos Padrões Neurológicos Básicos, aprendemos a nos equilibrar no desequilíbrio, passando de monocelulares em ambientes aquáticos, até anfíbios e répteis na transição para a terra e o céu (ar). Entre diferentes elementos do ambiente, desenvolvemos nossas diferentes habilidades de sensaçãosentimento-ação (Cohen, 1993), lidando com um mundo em constante inte(g)ração interno-externo. 


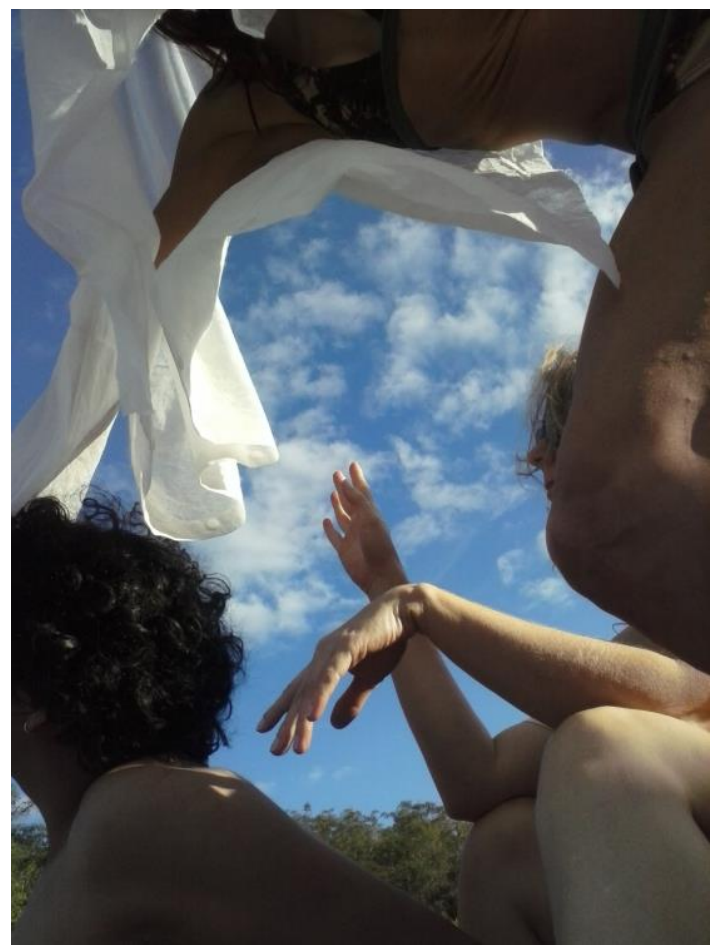

Figura 05. Thales Branche, Susanne Ohmann e Carla Antonello em atividade do Laboratório de Performance do PPGAC/UFBA em Lençóis BA, julho de 2013. Foto da autora.

Como somas em constante equilíbrio e desequilíbrio, a pesquisa hoje tem um papel ecológico de renovar nossa compreensão e atitude como simultaneamente passivos e ativos, dançando com(o) átomos, moléculas, células, letras, símbolos, signos e universos:

Laban argumenta ... que se a estabilidade e harmonia [dinâmicas] do universo são refletidas na célula, livre do controle da mente central, então essas qualidades podem ser ditas de terem existido antes do homem. Elas não são, consequentemente, assunto de seu controle, e não foram iniciadas por ele. Se elas não são feitas pelo homem, e nós aceitamos que elas existem, de onde elas se originam? É possível deduzir uma resposta a essa pergunta pela conclusão que Laban tirou de uma analogia baseada nos percursos dos elétrons. Enquanto a maioria dos elétrons segue tratos complicados, mas regulares, há alguns que não obedecem nenhuma lei física conhecida. Estes aparentemente exercitam a vontade livre na opção de seus percursos. (Thornton, 1971, p. 26-27).

Assim, pesquisa é o ato criativo de ser redescoberto e reinventar-se em comoção: "Em qualquer filme, peça, ou trabalho literário, estudiosos de mídia nos contam como determinar quem é verdadeiramente o personagem principal da estória - é o indivíduo que, ao final, mudou ao máximo" (Burger e Starbird, 2012, p. 8). Numa abordagem dinâmica e ecológica, a Pesquisa Somático-Performativa é da cena e para a cena, mas totalmente inclusiva. É através do modus operandi 
dinâmico (performativo) da cena (enquanto organismo vivo ou soma) que se articula e integra questões e aspectos MIT-disciplinares - a partir de então relevantes e coerentes à pesquisa em artes cênicas. Portanto, para utilizar essa abordagem, não é necessário ter nem a educação somática nem a performance como temas ou métodos de investigação, mas que a associação de ambas facilite e estimule o surgimento de perspectivas artísticas plurais e inovadoras, de aplicações irrestritas.

As contribuições da Pesquisa Somático-Performativa para "o conceito de pesquisa na pesquisa em artes" podem ser assim resumidas:

- A arte é o elemento-eixo da pesquisa; a arte determina o método a (des)(re)organização da pesquisa;

- Todo e qualquer elemento inserido na pesquisa vem por indicação da obra de arte - seu processo criativo, sua observação, sua recepção etc.;

- A coerência, relevância e inovação da pesquisa são criadas ao longo do processo, por se perceber e seguir o modus operandi da obra de arte em questão;

- A pesquisa é o "espaçotempo" da arte. O processo da pesquisa é arte, experiência estética, performance; não apenas compreendida como tal, mas realizada de forma artística. Todas as fases são mediadas e realizadas pela arte, inclusive a coleta, registro, observação e análise de dados. Por exemplo: entrevistas-intervenção, incorporação simultânea de leituras e/ou dados em laboratórios de performance, "observação realizadora" e análise em movimento de performances ao vivo e/ou em imagem (fotografia, vídeo, telepresença etc.);

- Todas as fases da pesquisa estão conectadas com/no todo, integrando dinamicamente pesquisador, tema e contexto;

- A criatividade é o eixo condutor relacional e imprevisível;

- Não queremos desviar nem escapar de conflitos, contrastes, ou paradoxos. Problemas apontam caminhos possíveis;

- Perguntas são parte fundamental do processo individual e coletivo, pois direcionam com flexibilidade, abrem caminhos e levantam direções possíveis, ao invés de enfocar em temas isolados;

- As "respostas" não concedem uma solução final; ao invés disso, são criações abertas, autônomas e relacionais imprevisíveis, através de meios múltiplos em pulsões espaciais, gradualmente perpetuadas em imagens e palavras; 
- Uso de todo e qualquer meio de impressão e expressão; multi, inter, trans-artes; a partir desse processo MIT-artístico, dialoga-se com qualquer área ou disciplina (MIT-disciplinar);

- Pesquisa é repadronização (repatterning), mudança ad infinitum, avançando ao recuar;

- Soluções inovadoras são mutantes, desenvolvem-se de forma imprevisível a partir de desafios, em Padrões Cristal, de Mudança ou Crescimento;

- A inovação e a mudança, apesar de imprevisíveis, ocorrem em Padrões Cristal, num dueto entre liberdade infinita e organização dinâmica e autônoma;

- Mais do que ser feita quantitativamente, a pesquisa se faz qualitativamente, numa dinâmica entre mover e ser movido, pesquisar e ser pesquisado, procurar e ser encontrado, perder-se e achar-se na diferença;

- Integração de identidades num soma fluido: sujeito e objeto, realizador e observador, artista-criador e pesquisador-analista;

- Na perspectiva somático-performativa, polaridades e diferenças não são separadas espacialmente. Ao invés disso, desenvolvem-se no "espaçotempo" umas das outras, como que se gerando recíproca e continuamente, em padrões espiralados imprevisíveis de dentro e fora e vice-versa, simultaneamente, sem separação nem união estável, mas conexão e desafio mútuo, em "constante mudança";

- Primazia da relevância autônoma, consistência somática e inovação espontânea, sem pressão quantitativa;

- Valorização da Sabedoria e Sintonia Somáticas (Nagatomo, 1992) no processo de investigação. A mente não é apenas função intelectual e cognitiva, mas é vivência explorada, informada e aprendida pelas células, corporificada; mente compreendida como "estado de consciência" e "estado de sensação" das células e sistemas corporais (Hartley, 1995). Inteligência abrangente, baseada numa sintonia sensível consigo e com o meio, em relações, conexões e integração;

- Pesquisa é compartilhar de pulsões (público, espaço, intervenção e escrita como dinâmicos), não competitivo, mas colaborativo, coletivo, politicamente pulverizado; reconhecendo e valorizando autonomias autoorganizadoras inter-relacionais; 
- Atenção aos detalhes como autonomias auto-organizadoras interrelacionais, a partir de uma perspectiva do todo: integração como pulsão espacial de sensação-emoção-intenção-intuição (peso-fluxo-focotempo);

- Valorização da intuição, que se manifesta em insights, imagens, visões, sensações, sensopercepção etc. ;

- Valorização do inconsciente, dos sonhos e dos estados alterados de consciência, bem como de todos os processos supostamente nãoacadêmicos (como, por exemplo, passeios, diversão e repouso) durante todo o processo de pesquisa;

- Integração consciente-inconsciente, lado direito e lado esquerdo do cérebro; valorização das diferentes ondas cerebrais, sem primazia de uma sobre a outra;

- Imagem somático-performativa (Fernandes, 2012b): imagem como integração entre movimento e escrita, sensação e cognição, desconstrução do simulacro;

- Técnica como conexão e diluição; sensibilidade; valorização da pausa e lentidão tanto quanto impulso e dinamismo; escuta somática;

- Integração entre passivo e ativo, recepção e impulso, receptividade e(m) ação, numa sabedoria micro e macro-cósmica, micro e macro-política;

- Ser testemunha, Ser movido, ser escrito, ser achado pelos autores, ser levado pelo tema e pelas perguntas etc. Não num ingênuo retorno ao "natural", mas numa investigação das forças que agem em tudo;

- Autor-pesquisador como facilitador de inteligências múltiplas;

- Pesquisa viva, dinâmica (não apenas por ser escrita ou lida de forma dinâmica, mas principalmente por perpetuar a des-re-organização pulsante da vida e da arte);

- Ritmo e Ecologia Somáticos: Valorização dos ritmos internos e da sincronicidade dos eventos; escuta somática para seguir impulsos em sintonia com o todo;

- Escrita viva, sensível e sensitiva, seguindo ritmos, cadências e ênfases da própria pesquisa, numa ordem quântica que se faz fazendo (não-linear);

- Processo de pesquisa em respeito com o tema esforço/recuperação, seguindo as necessidades somáticas de repouso, fruição e alimentação em todos os níveis; 
- Pesquisa e escrita como espaços pulsionais; espaço compreendido e vivenciado como pulsão e vibração intra, inter e transcelular (mineral, vegetal, animal, humana, atmosférica, planetária, galáctica, cósmica);

- Pesquisa e escrita como traços elípticos, parabólicos, e hiperbólicos no "espaçotempo" quântico (Traceforms em LMA); espaço ativo no processo criativo da pesquisa;

- Cada um de nós é um soma único, portanto a contribuição de cada um, num coletivo integrado, é única e inovadora, porém precisa ser realizada (performada);

- Ao revelar e descobrir, a investigação cria, abrindo, ao mesmo tempo, inúmeras possibilidades e mistérios provisoriamente indecifráveis (até que se soma-performatize novos caminhos, que por sua vez dispararão novos mistérios, ad infinitum). Pesquisa é mistério; decifrar tudo seria a morte da pesquisa;

- Pesquisa é pulsão espacial, sempre em processo (auto-criativo e relacional) como a vida e a arte.

A partir destas premissas, apresento a seguir os vinte princípios dinâmicos e abertos da Pesquisa Somático-Performativa identificados até o momento, os quais se dividem em fundantes, temáticos, e contextuais (Fernandes, 2013). Gradualmente, estes princípios organizaram-se em formas cristalinas como na Corêutica de Laban: dois grupos de quatro (dois tetraedros ou um hexaedro/cubo), um grupo de doze (icosaedro) e todos juntos num grupo de vinte pontos (dodecaedro).

Os quatro princípios fundantes são: Arte de/em movimento como elemento-eixo (a pesquisa nos guia em seu movimento); Processos e estudos têm constituição viva e integrada - soma; Ser guiado pelo impulso interno de movimento; Performance e multiinter-trans ou MIT artes como (anti-)método (por exemplo, modos performativos de coletar, registrar, observar e analisar dados, ler, escrever, fazer defesas públicas, palestras etc.).

Os doze princípios temáticos incluem: Pulsão espacial ou inteligências autônomas interrelacionais; Sintonia somática e sensibilidade (corpo como matéria e energia experienciados de dentro e com/no meio, em integração dinâmica no todo de sentimento, sensação, intenção, atenção, intuição, percepção e interação); Sabedoria Somática ou inteligência celular; Energia, fluxo e ritmo - ebulição e pausa - mover e ser movido; "Espaçotempo" quântico, simultaneidade e sincronicidade; Padrões Cristal, Repadronização e decolonização; Criatividade, imprevisibilidade e desafio; Conexões - 
fronteiras fluidas entre diferenças; Criação de associações e sentido a partir dos afetos e apoio do coletivo; Coerência interna e $(\mathrm{m})$ inter-relação; Imagem somático-performativa, Espiritualidade encarnada ou Soma sagrado.

Os quatro princípios contextuais são: Integração e consciência (g)local; Abertura participativa e poéticas da diferença; Sustentabilidade e ecologia profunda; Multi-InterTrans ou MIT disciplinariedade - arte como eixo de diálogo entre diferentes campos do saber.

Para finalizar, ressalto que a Pesquisa Somático-Performativa é inerentemente flexível e aberta às mais variadas modificações e influências, uma vez que suas características constitutivas - algumas das quais aqui apresentadas - estão em "constante mudança".

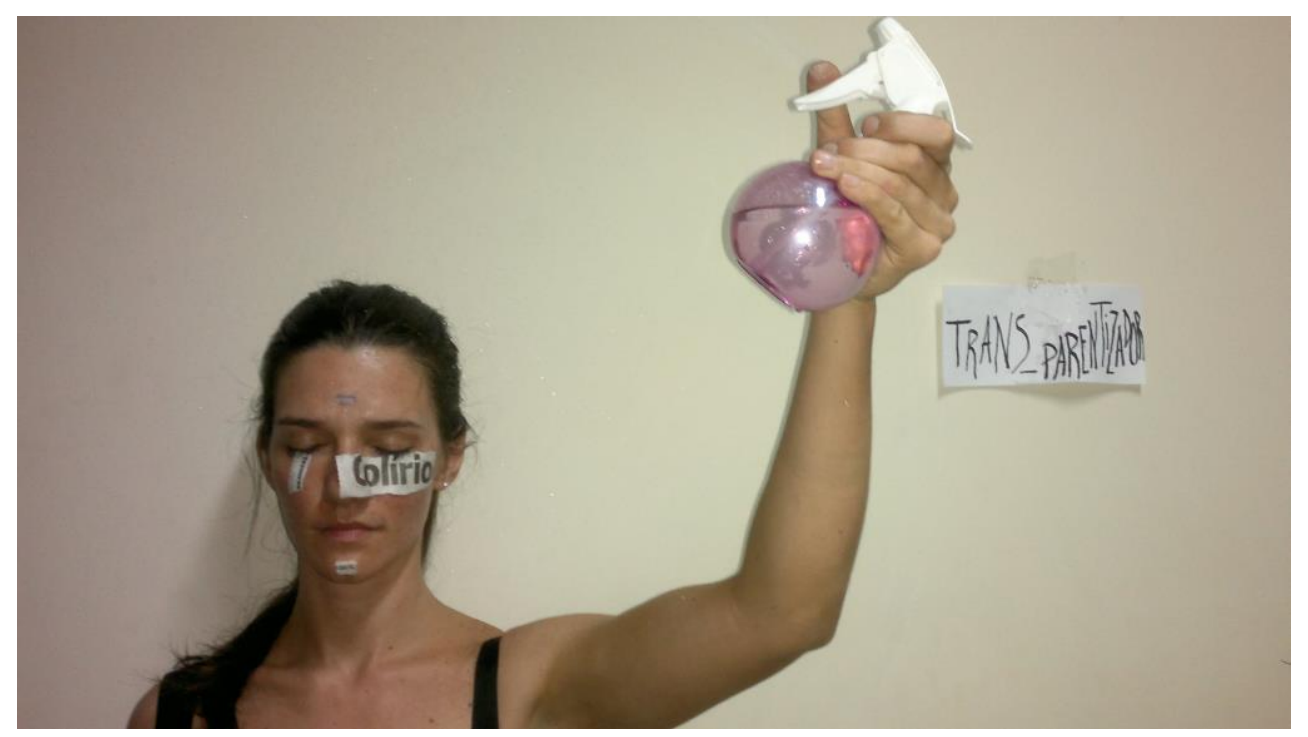

Figura 06. Mariana Terra soma-perfomatizando sua pesquisa de iluminação cênica no Laboratório de Performance do PPGAC/UFBA, junho de 2013. Foto da autora. 


\section{Referências}

ANDERSON, Laurie. Palestra (Lecture). New York University, 1993.

ANDERSON, Rosemarie. Embodied writing: Presencing the body in somatic research, Part I, What is embodied writing? Somatics, v. XIII, n.4, p. 40-44, spring/summer 2002.

ANDERSON, Rosemarie. Embodied writing: Presencing the body in somatic research, Part II, Using embodied writing in literature reviews, data collection and analysis, and presentation of findings. Somatics, v. XIV, n. 1, p. 40-44, fall/winter 2002/2003.

ANTOLICK, Matthew. Deep ecology and Heideggerian phenomenology. Tese de doutorado. (PhD) University of South Florida, 2003. http://scholarcommons.usf.edu/etd/1326.

BARRETT, Estelle; BOLT, Barbara (Org.). Practice as Research: Approaches to Creative Arts Inquiry. Londres: I.B.Tauris, 2007.

BARTENIEFF, Irmgard; LEWIS, Dori. Body movement. Coping with the environment. Langhorne: Gordon \& Breach Science Publishers, 1980.

BHARATAMUNI. The Nātya Śāstra. Translated into English by a Board of Scholars. Nova Deli: Sri Satguru, 2000.

BONDÍA, J. L. Notas sobre a experiência e o saber da experiência. Tradução de João Wanderley Geraldi. Revista Brasileira de Educação, Universidade Estadual de Campinas - Departamento de Linguística, Campinas, n. 19, p. 20-28, Jan/Feb/Mar/Apr, 2002.

COHEN, Bonnie Bainbridge. Sensing, Feeling, and Action: The Experiential Anatomy of Body-Mind Centering. Northampton, Mass: Contact Editions, 1993.

FARIAS, Sérgio. A MIT-disciplinariedade como desafio para os profissionais de arte-educação na contemporaneidade. In: CONSTÂNCIO, Rudimar (Org.) ArteEducação: História e praxis pedagógica. Recife: SESC Piedade, 2012, p. 29-33.

FÉRAL, Josette. O real na arte: a estética do choque. In: RAMOS, Luiz Fernando (Org.). Arte e ciência: Abismo de rosas. São Paulo: ABRACE, 2012, p. 77-94.

FERNANDES, Ciane. Como se move o que nos move? Variações Autênticas, Padrões Cristal e Pesquisa Somático-Performativa. Movement News. Edição Bilingue português/inglês. New York: Laban/Bartenieff Institute of Movement Studies, p. 68-73, Fall 2012a.

FERNANDES, Ciane. Imagem somático-performativa: força, conexão e integração. Comunicação (Oral Presentation). IX Colóquio Franco Brasileiro de Estética: Imagem e Corpo Performativo. Escola de Belas Artes da Universidade Federal da Bahia, setembro de 2012b.

FERNANDES, Ciane. Perforgrafias: Pulsões Espaciais Somático-Performativas. Revista A.Dnz. Santiago do Chile: Universidade do Chile, Faculdad de Artes, Departamento de Danza. Ano I, n.1, abril 2014, p. 60-71.

FERNANDES, Ciane. Princípios somático-performativos no ensino e pesquisa em criação. In: MARCEAU, Carole \& CAJAÍBA SOARES, Luiz Cláudio. (Org.). Teatro na Escola. Reflexões sobre as Práticas Atuais: Brasil-Québec. Salvador: PPGAC/UFBA, 2013, p. 105-115. 
FORTIN, Sylvie. O processo formativo como construção de novos procedimentos criativos. In: RAMOS, Luiz Fernando (Org.). Arte e ciência: Abismo de rosas. São Paulo: ABRACE, 2012, p. 115-139.

FOSTER, Hal. The return of the real. Cambridge, Massachusetts: The MIT Press, 1996.

FOUCAULT, Michel. The history of sexuality, Vol. 2. The use of pleasure. New York: Vintage Books, 1990.

HACKNEY, Peggy. Making connections. Total Body Integration through Bartenieff Fundamentals. Amsterdã: Gordon and Breach Publishers, 1998.

HANNA, Thomas. The Field of Somatics. Somatics, v. I, n.1, p. 30-34, Autumn 1976.

HARTLEY, Linda. Wisdom of the body moving. Berkeley: North Atlantic Books, 1995.

HASEMAN, B. C. Manifesto for Performative Research. Media International Australia incorporating Culture and Policy, theme issue "Practice-led Research", n.118, p. 98-106, 2006.

KAKO, Michio. Hyperspace: A scientific odyssey through parallel universes, time warps, and the tenth dimension. Oxford: Oxford University Press, 1995.

KESTENBERG, Judith S. The role of movement patterns in development. Vol. I. New York: Dance Notation Bureau, 1977.

LABAN, Rudolf e LAWRENCE, Frederick Charles. Effort. Economy of human movement. Estover: Macdonald \& Evans, 1974.

LABAN, Rudolf. A vision of dynamic space. Londres: Laban Archives \& The Falmer Press, 1984.

LABAN, Rudolf. Die Welt des Tänzers. Stuttgart: Walter Seifert, 1921.

LABAN, Rudolf. O Domínio do movimento. São Paulo: Summus, 1971.

NAGATOMO, Shigenori. Attunement through the body. New York: State University of New York, 1992.

PREVOTS, Naima. Zurich Dada and Dance: Formative Ferment. Dance Research Journal, p. 3-8, spring/summer 1985.

PRIGOGINE, Ilya. O fim das certezas: tempo, caos e as leis da natureza. São Paulo: Editora da UNESP, 1996.

SANTAELLA, Lucia. A relevância da arte-ciência na contemporaneidade. In: RAMOS, Luiz Fernando (Org.). Arte e ciência: Abismo de rosas. São Paulo: ABRACE, 2012, p. 61-76.

SCHECHNER, Richard. Future Nostalgias. Research in Drama Education, v.15, n.3, p. 309-315, Aug. 2010.

SHUSTERMAN, Richard. Consciência corporal. Tradução de Pedro Sette-Câmara. Rio de Janeiro: E Realizações, 2012.

THORNTON, Samuel. Laban's theory of movement. A new perspective. Boston: Plays, 1971. 